\title{
ANTI-MALARIAL POLICY IN THE MADRAS PRESIDENCY: AN OVERVIEW OF THE EARLY DECADES OF THE TWENTIETH CENTURY
}

\author{
by
}

\author{
V. R. MURALEEDHARAN and D. VEERARAGHAVAN *
}

The history of health care in colonial India was for long a neglected field of study. However, in recent years interest in the history of medicine and its role during the period of British rule has been growing, as is evident from the increasing number of studies published. ${ }^{1}$ While some attempts have been made to draw the broad outlines of the development of health policy at both an all-India level ${ }^{2}$ and at regional levels, ${ }^{3}$ the policies on specific diseases have received far less attention. ${ }^{4}$ This is particularly true of malaria. There is as yet no detailed history of anti-malarial measures in colonial India. ${ }^{5}$ Our desire to fill this gap in the existing literature on the history of health care is the basic motive for this paper, which attempts to trace the various anti-malarial steps taken by the government of Madras during the early decades of the twentieth century. We begin with a brief background to the nature of health care policy in the Madras Presidency and a summary of the debate on the nature of anti-malarial measures taken in the years following the discovery of the anopheles mosquito. We then focus our

* Both Dr V. R. Muraleedharan and Dr D. Veeraraghavan are faculty members in the Department of
Humanities and Social Sciences, Indian Institute of Technology, Madras (India), PIN: 600036.

We sincerely thank the referees for their valuable comments on this paper. We are however responsible for any errors that may remain.

${ }^{1}$ The following two books are the most recent additions to the existing literature: David Arnold (ed.), Imperial medicine and indigenous societies, New Delhi, Oxford University Press, 1989; and Poonam Bala, Imperial medicine and Bengal, 1850-1947, New Delhi, Sage Publications, 1991.

2 Radhika Ramasubban, Public health and medical research in India: their origins under the impact of British colonial policy, Stockholm, 1982.

3 J. C. Hume Jr., 'Colonialism and sanitary medicine: the development of preventive health policy in the Punjab, 1860 to 1900', Mod. Asian Stud., 1986, 20: 703-24. There are also two unpublished theses on public health administration in the Madras Presidency: Christopher J. Nirmal, 'A study of public health in the Madras Presidency, 1882-1912', Ph.D. thesis, University of Madras, 1970; and J. L. Yesudasan, 'Public health (sanitary) administration in the Madras Presidency, 1922-1942', M.Litt. thesis, University of Madras, 1949.

${ }^{4}$ This gap is being filled to some extent, see Arnold, op. cit., note 1 above.

${ }^{5}$ Mention however should be made of the following three studies that have dealt with malaria in some detail: Ira Klien, 'Malaria and mortality in Bengal, 1840-1921', Indian econ. and social Hist. Rev., 1972, 9: 132-60; Elizabeth Whitcombe, 'Irrigation', in Dharma Kumar (ed.), The Cambridge economic history of India, vol. 2, New Delhi, Orient Longman, 1983, pp. 637-737; and V. R. Muraleedharan, 'Malady in Madras: the colonial government's response to malaria in the early twentieth century', in Deepak Kumar (ed.), Science and empire: essays in Indian context, New Delhi, Anamika, 1991, pp. 101-12. 
attention on the efforts made to combat the disease between the two world wars. Broadly speaking, the anti-malarial efforts of the government of Madras entailed the development of (a) a quinine policy and a search for alternative drugs; and (b) effective location-specific preventive measures based on a clear understanding of socioeconomic conditions. We will deal with each of these points in turn and conclude with a summary of our observations.

I

Western medicine in colonial India was firmly established by the beginning of this century. By then a fairly elaborate, but by no means adequate, administrative machinery had been set up to look after the health of the people throughout the country, the Madras Presidency included. The health care system in that state underwent qualitative changes, especially during the inter-war years. In 1919, as a result of the Government of India Act, public health administration was transferred to the Indian ministers of the provincial governments. This made it possible for the Madras administration to experiment with certain tactics to combat disease. A series of legislative measures was introduced which show clear evidence of the provincial government's influence on health care between the wars; the most important of these were the Madras Medical Registration Act 1914, the Madras Prevention of Adulteration Act 1918, the Madras Nurses and Midwives Act 1926, and the Madras Public Health Act 1939.

Up to the middle of the eighteenth century, European medicine, brought to India by the colonizers, served to protect the health of only the Army and the European community. As Arnold has pointed out, in nineteenth-century colonial India, western medicine "was constrained ideologically, financially and politically from broader and more effective involvement in the health of the population". 6 None the less, health care slowly expanded, ${ }^{7}$ although the overall thrust of the system was biased towards curative services, and it suffered often from lack of funds. The Madras government was guided all along by the principle of laissez-faire as far as this matter was concerned and so it sought for a means of developing a cheap method of health care whereby the state's expenditure would be reduced, and the patients would meet the cost themselves. ${ }^{8}$ Unfavourable economic conditions, such as the depression of 1929-32, contributed to the Madras government's decision to rely increasingly on private medical practitioners, alternatively called the Independent Medical Profession, to provide health care to the mass of the population. This is evident if one looks at the history of rural health care, particularly the Subsidised Rural Medical Relief Scheme, in the Madras Presidency during the inter-war years. When the scheme was introduced there was a discussion about the way in which the provincial government should, over

\footnotetext{
${ }^{6}$ David Arnold, 'Medical priorities and practice in nineteenth-century British India', S. Asia Res., 1985, 5: $167-83$.

${ }^{7}$ For a summary of the reasons that forced the colonial government to extend health services beyond the needs of the Army and the European community, see Arnold, 'Introduction: disease, medicine and empire', in Arnold, op. cit., note 1 above, pp. 1-26.

8 V. R. Muraleedharan, 'Development of health care system in the Madras Presidency, 1919-1939', Ph.D. thesis, Indian Institute of Technology, Madras, 1988.
} 


\title{
V. R. Muraleedharan and D. Veeraraghavan
}

a period of time, phase itself out of supporting the health services, leaving their administration to be taken over ultimately by private medical practitioners. This reflected a laissez-faire attitude in a larger sense. Medical relief was essentially treated as a local affair by the provincial government and therefore it gave local bodies very little financial assistance. ${ }^{9}$ Given the nature of the Madras government's policy, it is important to know how it responded to certain widely prevalent communicable diseases. The history of this aspect of health care offers an insight into the nexus of various forces that determined the nature, timing and effectiveness of the administration's response. This can best be illustrated through an account of the various efforts made by the Government of India to combat malaria, the disease that was perhaps most feared. It was considered by the British to be "a problem of Imperial Magnitude" 10 and one of the principal menaces to British life and health in the empire. The social and economic costs to India were estimated to be enormous, as the following comment made in 1934 by J. A. Sinton, a pioneer in malarial research in India, reveals:

\begin{abstract}
Malaria gives rise to the greatest economic problem with which India is faced. The financial losses to the individual and the family alone have been calculated at not less than Rs. 11,000 lakhs annually, or about 80 million sterling per annum. This apart from the effects of the disease upon all aspects of the labour problem, and thus upon the fullest exploitation of the natural resources of the country and the successful development of her manufacturing and other industries. While it is not possible to evaluate with any degree of accuracy the immensity of these direct and indirect losses, there is little reason to doubt that they must run into unbelievable millions of pounds of sterling each year. ${ }^{11}$
\end{abstract}

The discovery by Ronald Ross in 1898 that malaria was carried by the anopheles mosquito was ranked "not only as the greatest of India's medical triumphs, but as one of the greatest discoveries of modern times". ${ }^{12}$ It was now possible to think of more coherent preventive measures. The fact that the transmission of the disease could be interrupted by destroying the vector also made it practicable for tropical sanitarians to make more accurate studies of the habits and breeding places of different species of anopheles.

Malarial fever was as prevalent in the Madras Presidency as it was in other parts of colonial India. The city of Madras and its surroundings profited from the early anti-malarial measures despite the fact that they suffered less from malarial fever than the other parts of the Presidency. The reason for this could be that the city had a higher proportion of Europeans than the rest of the State. Unlike the plague which

\footnotetext{
${ }^{9}$ V. R. Muraleedharan, 'Rural health care in Madras Presidency: 1919-1939', Indian econ. and social Hist. Rev., 1987, 24: 323-34.

${ }^{10}$ That was how Lord Minto, Viceroy and Governor-General of India, characterized malaria in his inaugural address of the Imperial Conference, 12-18 October 1909, held at Simla, Government of India, Proceedings of the Imperial Conference on Malaria, Simla, 1910.

11 J. A. Sinton, 'What malaria cost India, nationally, socially, and economically (concluded)', Records of Malaria Survey of India (hereafter, RMSI), 1936, 6: 91-169.

${ }^{12}$ R. McCarrison, 'India and medical progress', Br. med. J., 1917, ii: 110.
} 


\section{Anti-malarial policy in the Madras Presidency}

was concentrated in urban areas where the most intensive preventive operations were carried out, ${ }^{13}$ malaria was more severe in the countryside where, by comparison with the towns, few anti-malarial measures were taken.

In the years following Ross's discovery a series of discussions took place amongst the policy makers in the Madras government about the feasibility of applying anti-malarial measures as suggested by Ross. We give below a brief account of that discussion, before going on to the later period.

Late in 1901, Ronald Ross wrote from Liverpool to the Under Secretary of State for India on the subject of "mosquito brigades for India" as a preventive measure against malaria. ${ }^{14}$ Until then, the only method employed against the fever had been the administration of quinine to infected persons. Ronald Ross believed that the elimination of malaria depended on the destruction of the mosquitoes rather than on massive use of quinine. From his experiments in Sierra Leone in Africa, he felt that mosquito brigades were the best means available to eliminate the insects, and he therefore suggested that they be tried out in India as well. His conception of a "mosquito brigade" can best be described in his own words:

The local health officer or district medical officer, or other persons interested in the subject, should at once engage the services of an intelligent headman and a sufficient staff of workmen, who will constitute the brigade. These should be first instructed how to find larvae of mosquitoes in vessels of water in the vicinity of houses, in pools of stagnant water on ground, in garden, cistern, drains and so on. Native agents carefully selected will be found quite capable of learning the work. ${ }^{15}$

He was convinced that these operations "are not so formidable as it may at first sight appear"; for him their guiding principle was contained in three words: "No Stagnant Water". ${ }^{16}$ Ross was also opposed to starting operations over too large an area. Instead, he suggested that "it is best to begin in the immediate vicinity of the houses of Europeans ...". 17 From such a beginning, he thought, the operations would take shape as they evolved. He was certain that as soon as the neighbouring breeding places were carefully removed "the winged insects will vanish as if by magic". ${ }^{18}$

These suggestions were communicated to the various provincial governments by the Government of India. While briefing them on the subject of mosquito brigades, W. S. Marris, Under Secretary to the Government of India, Home (Medical) Department, observed that "it is highly desirable that a knowledge of the now accepted fact that measures such as those desired by Major Ross to a great extent ensure immunity from malarial fevers should be widely disseminated among the

13 David Arnold, 'Touching the body: perspective on the Indian plague, 1896-1900', in Ranajit Guha (ed.), Subaltern studies, vol. v, Writings on south Asian history and society, New Delhi, Oxford University Press, 1987, pp. 55-90.

${ }_{14}$ Tamil Nadu Archives, Madras (hereafter TNA), Ronald Ross, 'Mosquito brigade for India', in Government Order (hereafter GO) 33 (Public Department, hereafter Public), 9 February 1902.

15 Ibid.

16 Ibid.

17 Ibid.

18 Ibid. 


\section{$V$. R. Muraleedharan and D. Veeraraghavan}

population" ${ }^{19}$ But he also clearly advised that the "sphere of operations must be restricted by practical considerations". Marris felt that a "beginning must be made gradually, and that ... to secure systematic and thorough operations in a few selected places would be better than to attempt to deal with areas too extended". He feared that if it were tried in many places and did not succeed, "it would bring the remedy into disrepute; whereas definite success in a few places might bring home to the people the ease with which they could secure comparative immunity from malarial fevers". The government of Madras was asked to use its discretion in deciding to what extent and in what areas action should be taken and was asked to report to the Government of India any success attained by measures of the kind which Ross advocated.

But it was not possible for the Madras government to experiment with the mosquito brigades because the idea was not welcomed enthusiastically by all the health officials concerned. By the end of 1902, the Surgeon-General with the government of Madras, S. D. Sinclair, received reports from 49 health officials in the Presidency on the use of mosquito brigades along with several different options. ${ }^{20}$ While some officials were eager to experiment with the brigades but felt constrained by lack of financial resources, others argued that "so long as wet cultivation in and around towns and villages is permitted, so long as wells, swamps, huge ravines, ponds, tanks etc., allowed to exist, mosquito brigade operations would be comparatively useless and the results might bring the remedy into disrepute". ${ }^{21}$ As for the city of Madras, a small brigade was appointed on an experimental basis to cover some parts of the city. But the health officer of the Madras Corporation was strongly opposed to brigades being used in other parts, as he considered that "it was not a very suitable place for such operations". He felt that it was necessary to wait until the main drainage system had been completed and the water supply improved, gradually allowing wells to be closed, before the efforts of the mosquito brigades, tiny by comparison, could be used with any hope of success in the municipality. Among the foreseen difficulties, the most insurmountable appeared to be that of making wet cultivation around villages or towns illegal. In fact, Sinclair argued that the prohibition of the cultivation of paddy fields in malarious areas would involve such a large expenditure as to be entirely impracticable.

Since the opinion of the health officers was divided, the government of Madras was faced with the question of whether or not it was worth spending money on the crusade against mosquitoes. What came out clearly was the realization that the costeffectiveness of the operations suggested by Ross would be low unless they were undertaken simultaneously with a number of other measures as well, something which was not possible or even practicable. As G. S. Forbes, Secretary to the Public Department, reasoned: "it was a mistake to believe that there was no use in doing

\footnotetext{
${ }^{19}$ Letter from W. S. Marris, Under Secretary to Government of India, Home (Medical) Department to the Chief Secretary to the Government of Madras, 16 December 1901, in TNA, GO 33 (Public), 9 February 1902.

${ }^{20}$ Letter from S. D. Sinclair (Surgeon-General) with the Government of Madras to the Chief Secretary to the Government of Madras, 22 May 1902, in TNA, GO 1173 (Public), 19 November 1902.

${ }^{21}$ Ibid.
} 
anything at all unless every piece of stagnant water was either treated or obliterated ... and there was no need to wait until big projects such as drainage schemes were undertaken, or all wells closed or wet cultivation prohibited in malarial zones ...". ${ }^{22} \mathrm{He}$ left it however to the district boards or municipalities to select some villages or portions of a town for experiment urging that "in the interest of science, the measures advocated by Major Ronald Ross should be given a trial where practicable". 23

A series of mixed reactions from the various district boards and municipalities followed. Twelve of the district boards and thirty-nine municipal councils made it clear that they did not intend to take any action in the matter; while the rest were either willing to carry out the experiments or had already started to do so. ${ }^{24}$ Those not willing to take any action gave a variety of reasons. Some were very sceptical of such measures. For example, the district board of Ganjam passed a resolution that "in the opinion of the board, the scheme is impracticable and would involve expenditure without any corresponding advantage". Lack of funds was also cited by some boards and municipalities. Curiously, many of the boards and councils even claimed that it was unnecessary to take any action because malaria was not at all common in their regions, despite evidence to the contrary.

Because of this division of opinion, the government found it difficult to formulate any concrete plan. This only meant further delay in adopting Ross's proposals even at an experimental level. ${ }^{25}$ Clearly, one of the main problems in combating malaria was the delay between the discovery of the aetiology of the disease and the practical application of this knowledge. This is reflected in the following comment made in 1936 by G. G. Jolly while reviewing progress in medical research in India:

years ago the crying need was for knowledge of the mode of spread of our main diseases such as malaria and plague. Today we still have a vast amount to learn, but perhaps our greater problem is the successful application of the theoretical knowledge we already possess. ${ }^{26}$

At the level of government policy, what followed was an increasing reliance on palliative measures of temporary value. Research on methods of treatment, especially with the use of quinine and its substitutes, received greater attention in the following decades.

\section{II}

The question of "cinchona policy" or, as it was alternatively called, the "quinine policy", was plagued with many difficulties. There were a number of unanswered questions, which revealed clearly where the gaps in knowledge lay, and the directions

\footnotetext{
22 Notes by G. S. Forbes, dated 28 October 1902, in TNA, GO 1173 (Public), 19 November 1902.

23 Ibid.

24 TNA, GO 1378 (Local), 30 October 1903.

${ }^{25}$ For a detailed account of the discussion, see Muraleedharan, 'Malady in Madras', in Deepak Kumar, op. cit., note 5 above.

${ }^{26}$ G. G. Jolly, 'Medical research in India', Indian Medical Gazette (hereafter, IMG), 1936, 71 : 42.
} 


\section{R. Muraleedharan and D. Veeraraghavan}

in which further inquiries should be continued. The central questions were essentially: ${ }^{27}$

(a) How do malarial parasites produce the symptoms of malaria?

(b) How does man overcome malarial infection?

(c) What is the best drug to use?; what is the best way of administering it?

To put it differently, these questions were concerned with the relationship between host, vector, parasite and the environment. More research was required to provide the answers which would lead to an understanding of malaria in relation to local conditions including geographic, socio-economic and cultural factors. The government of Madras had, by early 1930 at least, taken up the following position concerning the drug to be used against malaria:

To hope that this [quinine] alone would banish malaria would be to court failure. It does certainly cure an attack and does relieve suffering. Unfortunately, it cannot prevent relapses, and it is now definitely shown that it is not a prophylactic either. Quinine is at best an auxiliary to other and more permanent measures directed against the destruction of anopheles mosquitoes and breeding places. ${ }^{28}$

None the less, the government felt that since "it would be impossible and impracticable for financial and other reasons to adopt anti-mosquito measures, quinine is bound to remain the only mainstay." 29 The various studies conducted later in the 1930s also indicated that quinine could not serve as a prophylactic measure but would remain as the mainstay of all forms of treatment of malarial fevers. ${ }^{30}$

The high cost of quinine was also an important factor to be considered. The price was considerably influenced by Java, which produced more than 95 per cent of the total world output, thus enjoying a virtual monopoly of the market. ${ }^{31}$ However, the Government of India retained the power to regulate the price and production of quinine within India. By the early 1920 s, the price was fixed at approximately Rs. 18 per pound, though the cost of production in government-owned factories in Madras was only Rs. 13.9 per pound, and in Bengal it was only Rs. 6.5 per pound. ${ }^{32}$ The reason for the high price, the Government of India argued, was that if any attempt was made to sell quinine in India at a price below that of the world market, Indian quinine would immediately be bought up by agencies outside the country. ${ }^{33}$ This pricing policy was

\footnotetext{
27 There were many other unanswered questions of equal importance. For example, it was known that various species of anopheles mosquitoes existed, and that each of them had a specific breeding site, some preferring sluggish water, some running streams. "But there are a hundred and one facts which may profoundly affect the breeding of mosquito larvae of different species. A slight change in the mineral content of water may transform a breeding ground into one quite unsuitable for the larvae"; there was also little knowledge "about the natural enemies of mosquitoes, and even less about their natural diseases". see 'The future of malaria control in India' (editorial), IMG, 1927, 62: 27-32.

28 TNA, GO 786 (Public Health Department, hereafter P.H.), 8 April. 1932.

29 Ibid.

$30 \mathrm{~J}$. A. Sinton, 'A suggested standard treatment of malaria based upon the results of the controlled investigation of over 3700 cases', IMG, 1930, 65: 603-20; and R. H. Chopra, 'The present position of anti-malarial drug therapy in India', IMG 1938, 73: 418-23.

${ }^{31}$ Henry Gidney, 'Quinine problem in India', Indian med. J., 1937, 31: 371-4.

32 Ibid.

33 Ibid.
} 
continued despite the fact that there was a great need for the drug. One obvious result was that the Government made a profit from the sales. But it should also be noted that because of the high price not all that was produced could be sold. The situation was characterized by a very great need, but, at the same time, by a low level of demand. In this context, the need for substitutes for quinine was felt all the more acutely. These were expected to be as effective as quinine against malaria and, at the same time, to cost less, so that the demand for anti-malarial drugs would increase. But it was not an easy task to introduce the substitutes that existed onto the market.

There was first of all the problem of convincing the medical profession of the value of the substitutes. As one of the editorials of the Indian Medical Gazette in 1941 commented: "the demand for pure quinine originated with the medical professionals and it was found difficult to change their choice of drug." 34 This was one of the major restrictions on evolving the best possible policy to combat malaria. In fact, some alternatives to "pure quinine alkaloid" were available, ${ }^{35}$ although no one was certain as to which and in what combinations they could be used effectively. By 1930, various studies had already been done on the relative efficacy of cinchona febrifuge, and of individual alkaloids as substitutes for pure quinine ${ }^{36}$ Reviewing the existing evidence from various sources in 1931, J. A. Sinton made the following observation:

There seems to be few workers who dissent from the opinion that in medical doses this drug is little inferior to quinine in the production of a clinical cure in ordinary cases of malaria, indeed some consider it more efficacious. Although it has not been confirmed that this drug is more efficacious in the production of a permanent cure in chronic benign tertian malaria, yet the evidence would seem to indicate that it is only slightly inferior to quinine in the same doses in ordinary cases of both benign and malignant tertian malaria. ${ }^{37}$

It was thought that by a judicious selection of strains of Cinchona succiruba (a variety of cinchona bark) it would be possible to minimize the toxic effects of cinchona febrifuge. ${ }^{38}$ But the market was flooded with cinchona febrifuge with varying proportions of different alkaloids. ${ }^{39}$ Although the combined effects of these mixtures were appreciated by the medical community, they had no "standard" which they could use for mass treatment. Therefore, in order to suggest a standard for cinchona febrifuge (alternatively called "total-cinchona-alkaloids") the League of Nations' special malaria commission surveyed the Indian sub-continent in 1929. The commission suggested a standardized preparation known as totaquina. ${ }^{40}$ But the

\footnotetext{
${ }^{34}$ Quoted in 'The need for a cheap and efficient anti-malarial drug in India' (editorial), IMG, 1941, 76: 225-8.

${ }^{35}$ For a detailed account of what constitutes cinchona bark, refer 'The Total Cinchona-Alkaloids' (editorial), IMG, 1934, 69: 215-17.

$36 \mathrm{~J}$. A. Sinton, 'The relative values of the cinchona alkaloids in the treatment of malarial fevers', RMSI, 1931, 1: 451-72.

37 Ibid, p. 464.

38 Ibid, p. 465.

39 Ibid, pp. 465-9.

40 The main advantage of this standardized mixture of alkaloid (totaquina) over other mixtures (cinchona febrifuge) was that in the former "a minimum of $15 \%$ of quinine" was present. For details see "Cinchona Policy” (editorial), IMG, 1932, 67: 393.
} 


\section{$V$. R. Muraleedharan and D. Veeraraghavan}

problem was not just one of suggesting a standard preparation. Again, as already noted, the medical profession was not yet ready to accept it. In 1931, an Indian Medical Gazette editorial commented that "greater efforts must be made to educate first of all the medical profession to accept the alternative to quinine". ${ }^{41}$ Besides, in the case of totaquina, its efficacy had yet to be demonstrated clinically under varying Indian conditions. ${ }^{42}$

In 1934, J. A. Sinton again sought to dispel the general scepticism, especially prevalent among medical men, about the effectiveness of existing substitutes for pure quinine. He firmly believed that "a mixed alkaloid preparation of the nature of totaquina would probably be little, if at all, less valuable than quinine for mass treatment as carried out in the tropics." 43 But there was no sign of any change in the demand for pure quinine by the medical profession during the 1930s. ${ }^{44}$ Apart from the problem of finding substitutes for quinine alkaloid, the question of distribution of these drugs in malarious regions continued to pose serious problems. ${ }^{45}$ Even as early as 1909, Lt.-Col. Leslie, the Sanitary Commissioner with the government of Madras, lamented that "given an efficient organisation, some proportion of this suffering and loss due to malaria is preventable by means already in power." 46 In 1934, Sinton echoed the same opinion: "the more urgent problems at the moment [that] confront India in connection with the treatment of her large malarious population are more closely allied with the provision of means of distribution of treatment to the malarious areas of the country rather than the standardisation of cinchona febrifuge". ${ }^{47}$

To summarize, we can say that as far as quinine policy in the Madras Presidency was concerned, it was not only lack of knowledge of effective therapeutic measures but equally the lack of organised means of distribution that were responsible for the failure to combat malaria.

\section{III}

Although complete eradication of the disease by drugs alone was accepted as impossible, the value of the therapeutic approach in preventing many deaths from it was recognized and appreciated by the medical community and the government. In the last section, referring to some of the issues involved, we showed the limitations of such an approach and of its benefits to the health of the people. The other method involved devising preventive measures to suit the areas known for malaria. These had to be planned "with due weightage being given to the physical and geographical features, the social and economic status of the people and the financial stability of the

\footnotetext{
41 'The Quinine Policy', (editorial) $I M G, 1931,66: 522$.

${ }^{42} I M G, 1934$, op. cit., note 35 above, p. 216.

$43 \mathrm{~J}$. A. Sinton, 'The standardisation of mixed preparation of the cinchona alkaloids in relation to Indian conditions', RMSI, 1934, 4: 5-13.

44 IMG, 1941, op. cit., note 34 above, p. 228.

45 TNA, GO 786 (P.H.), 8 April 1932.

46 J. T. W. Leslie, 'A proposal for the further investigation of malaria in India', (reprinted in) RMSI, 1931, 1: 92 .

${ }^{47}$ Sinton (March 1934), op. cit., note 43 above, p. 13.
} 


\section{Anti-malarial policy in the Madras Presidency}

authorities concerned in each area investigated."48 Therefore preliminary in-depth studies of those regions had to be carried out before any work could begin. The first such study was undertaken in 1911 in Ennore (then a small village on the east coast, about 12 miles north of the city of Madras). Anti-malarial work based on the results was carried out between 1911-1914. The outbreak of war in 1914 brought an abrupt end to the schemes "although they were sufficiently advanced to bear fruitful results". ${ }^{49}$ However, albeit in a spasmodic manner, anti-malarial operations in Madras continued until 1927 when the government at the suggestion of Lt.-Col. A. J. H. Russell, the Director of the Public Health Department, showed an interest in formulating and starting up a new scheme for dealing with the problem of malaria in the Presidency. Col. Russell urged that the government should undertake "systematic and adequate investigation and research on malaria as a necessary step towards the purely practical application of preventive measures." ${ }^{50}$ As a result, the government of Madras appointed, in 1927, K. R. Rao as a special malaria officer with a staff of one assistant surgeon, two laboratory assistants (and a clerk and a peon) to investigate the malarial conditions in selected areas, and to advise the government and the local bodies on the measures to be taken to eradicate the disease. ${ }^{51}$ While the government accepted Col. Russell's proposals for surveys to be carried out over a period of two years, it insisted that they should be confined to two or three localities only, particularly to those municipalities well known for malaria. The government was keen that preventive measures arising out of such work should be "within the financial capacity of the government and of the local bodies concerned". 52 As a result, malaria surveys were undertaken from 1927 onwards beginning with Bellary town and followed by others. But soon it was found that it was not "economically sound" to restrict the scope of the work in the manner originally planned. The reasons for this were given by the special malaria officer:

For one thing, recommendations and suggestions made for the suppression of malaria for any one place could not, for obvious reasons, be brought to any material form or shape until after the lapse of long time. For another thing, the local bodies who were actually called upon to execute the proposed anti-malarial measures pleaded incapacity on financial grounds. For a third thing still, even where a local authority was willing to do its part, it had to await the solution of conflicting interests of the several authorities responsible for the area under question. Meanwhile, reports of outbreaks of malaria and requisitions for carrying on investigations in other parts came pouring in. The government have, therefore, had to relax their resolution of restricting the work of investigation to two or three municipal areas as originally framed, and to call upon the special malaria officer to take up the inquiry of the malaria problem in other areas. ${ }^{53}$

\footnotetext{
${ }^{48}$ K. R. Rao, 'Note on the present state of knowledge about malaria in the Presidency of Madras', RMSI, 1931, 1: 483.

49 Ibid, p. 474.

50 Ibid.

51 Ibid.

52 Ibid. p. 475.

53 Ibid.
} 


\section{R. Muraleedharan and D. Veeraraghavan}

By 1930, a malaria survey had been conducted in 40 areas in different parts of the Presidency. Essentially, it consisted of the collection of the spleen and parasite rates in those areas. Though it was too early to map out a full geographical distribution of anophelines in the Presidency, the survey revealed certain important features about the distribution of malaria: (a) that $\boldsymbol{A}$. culicifacies was the most common carrier of the disease; and (b) that malaria was "prevalent to a variable extent in almost all parts of the Presidency at one part or the other". ${ }^{54}$ More importantly, the survey threw some fresh light on the nature of malaria and its connection with irrigation channels and wet cultivation in the inland parts of the state. As the special malaria officer put it:

The crux of the problem still is in the areas under smaller or bigger irrigation projects. In a purely agricultural country like ours, where more than 95 per cent of the population has to depend for their living on what they can grow on land, one could only recommend the abolition of irrigation with great searching of heart. The alternative measures for conserving the numerous irrigation channels in a cleanly state, or for delimiting the areas under cultivation where feasible beyond the radius of half a mile of the village-site, are often put forward. But on account of the conflicting interests of the several authorities concerned, no progress has been possible. ${ }^{55}$

He further added that the Revenue and the Public Works authorities should realize "how necessary it is to ensure that the very facilities that are intended to give the ryot his daily bread do not act as his 'death trap', as well". 56

Malaria in Madras thus posed complex problems which were difficult to solve. $A d$ hoc investigations and tinkering with the problem here and there would not bring forth any fruitful results. This led the government to agree to establish a permanent organization which would continue investigation and research into the problem and evolve a systematic policy over a period of time. One could say that this was the beginning of a series of important studies systematically carried out in South India with the aim of gaining a better understanding of malaria and of evolving preventive measures suited to local conditions. One such study started in 1936, was undertaken in the Pattukkottai taluk in the Tanjore district by the Department of Public Health in co-operation with the Rockefeller Foundation and the King Institute of Preventive Medicine (Guindy, Madras). This taluk was chosen for a detailed malaria survey because it was suspected to have become malarious only after it had begun to receive water from the Mettur-Cauvery irrigation project from 1933-34. ${ }^{57}$

What follows is a brief outline of these investigations on the nature of malaria in the Pattukkottai taluk, conducted in the field. They took into account geographic factors and local cultivation practices. This case study highlighted issues that the government had to bear in mind while formulating anti-malaria policy in any region.

\footnotetext{
54 The survey collected details such as spleen rate, parasite rate, name of the species, nature of the breeding ground, in 40 different parts of the Presidency. Ibid., pp. 486-97.

55 Ibid., p. 484.

56 Ibid., p. 485.

57 The Pattukkottai taluk in Tanjore district covered an area of 433,500 acres, of which $26 \%$ was under cultivation (1931 figures). The northern and eastern portions of Tanjore district formed the delta of the Cauvery river.
} 
Because of the lack of similar studies in other parts of the Presidency, only the results gained from the Pattukkottai taluk are summarized here and we do not discuss the question of malaria caused by the introduction of irrigation facilities in other areas of colonial India. ${ }^{58}$

The Pattukkottai taluk was not malarious until $1933 .{ }^{59}$ Before that time it was a dry zone with groundnuts as the most important crop, but during that year the canal system became operable so that it received water from about mid-June to the following mid-February. No drainage canal was provided for the irrigation system in the taluk or elsewhere, with the result that water accumulated in low-lying places. Clearly, the introduction of the Mettur irrigation system caused a number of changes in the taluk, some of the most important being: ${ }^{60}$

(a) Wet paddy cultivation increased, replacing the earlier chief crop, groundnuts; the monetary value of the land also was enhanced;

(b) Wet weather streams carried more water and were dry for a shorter time than previously;

(c) Tanks which used to dry up for several months each year, now were dry for a shorter time;

(d) Low-lying fields became waterlogged as a result of a rise in the sub-soil water level; this offered more scope for farmers to dig many shallow wells for irrigation during the off-season;

(e) Borrow pits, made for various reasons, and ditches, formerly dry most of the year, became filled with waste irrigation water, and remained "full during the season, and thereafter for varying periods".

All these changes were suspected to be the cause of the noted increase in the incidence of malaria in the Pattukkottai taluk from 1934 onwards. Compared to 1933, the proportion of malaria cases to the total number of patients treated in the government hospital in Pattukkottai town increased 4 times in 1934, 15 times by 1935, and 10 times by 1936 and $1937 . .^{61}$

The malaria season in the Pattukkottai taluk lasted from July to January and the off-season from February to June. It was observed that in Pattukkottai there were certain specific ways in which irrigation facilitated the development of the malaria carrying mosquitoes, $A$. culicifacies. As a result of a preliminary study carried out in Pattukkottai taluk between July 1936 and March 1938, Russell and his team discovered an intimate association between the anopheline carrier, $A$. culicifacies, and irrigation water. Their evidence showed that malaria became widespread only after the irrigation system was opened. It was concluded that "the malaria in Pattukkottai was traceable to the effects of the Mettur-Cauvery irrigation system as applied to this taluk."62 However, the relative contribution of irrigation to the incidence of malaria

\footnotetext{
${ }^{58}$ For a discussion on a similar experience in the Punjab, see Whitcombe, op. cit., note 5 above.

59 P. F. Russell, M. K. Menon, and T. R. Rao 'Epidemiology of Malaria in Pattukkottai Taluk, Tanjore District, Madras Presidency, India', Journal of the Malarial Institute of India (hereafter JMII), 1938, 1: 285-326.

60 Ibid., p. 289.

61 Ibid.

62 Ibid.
} 


\section{R. Muraleedharan and D. Veeraraghavan}

could not be exactly estimated. ${ }^{63}$ It was also argued that it was not irrigation per se but "defective and untidy irrigation", and waste irrigation water in particular, that were the sources of malaria. ${ }^{64}$ Absence of drainage facilities, and a lack of control over field channels which caused a rise in the sub-soil water level, encouraged the breeding of $A$. culicifacies. As well as this, a number of other factors, such as improper maintenance of canal banks, defective distribution chambers etc., were also found to be contributing to the spread of the disease. ${ }^{65}$

As a first step towards permanent preventive measures, the elimination of waste water was recommended to the government of Madras by the Rockefeller study team in 1938. They suggested some action be taken immediately, for example the installation of water-tight sluices, as there was "no sluice in Pattukkottai which can be properly controlled." 66 The government agreed to experiment with this proposal. ${ }^{67}$

The method of cultivation, especially in the rice growing areas, was recognized as being another important factor in the spread of malaria. It is significant that not all rice producing areas were malarious. Studies carried out in Bengal and the Punjab showed varying degrees of relationship between rice cultivation and the prevalence of the disease. ${ }^{68}$ In the case of the Madras Presidency itself, the greatest rice growing areas (namely the deltaic region of Tanjore and Trichinopoly, Kistna and Godavari districts) were not malarious. ${ }^{69}$ More specifically, within the Tanjore district there were two regions where rice was cultivated, namely the delta and the Pattukkottai taluk. The former was free of malaria, while the latter (from 1933) was not. This seemingly paradoxical situation was attributed to the fact the "the numbers of A. culicifacies present in the delta were markedly fewer than in the Pattukkottai taluk." 70 But this presented another question: why was this the case given the fact that in both the areas rice was grown by wet cultivation? The answer was found mainly in the different cultivation methods practised in these two regions:

The vector $A$. culicifacies thrived mostly in wet fallow fields and persisted in transplanted rice fields, and disappeared from growing fields. Their disappearance

${ }^{63}$ This was also the case in the Punjab. Whitcombe mentions the conflicts of opinions between the irrigation engineers and the malariologists in the Punjab on the contribution of irrigation to the spread of malaria, see Whitcombe, op. cit., note 5 above.

${ }^{64}$ P. F. Russell, 'Malaria due to defective and untidy irrigation: a preliminary discussion', JMII, 1938, 1: 348. C. A. Gill, from the experiences in the Punjab province, concluded that "an appreciable increase in the incidence of malaria is not a necessary concomitant of canal irrigation, but that canal irrigation may become gravely prejudicial to health when it is wrongfully applied or improperly carried out". For details see G. A. Gill, 'The relationship of canal irrigation and malaria', RMSI, 1931, 1: 421 .

${ }^{65}$ Excessive supply of water above the designed carrying capacity of the canals "causes a great deal of mosquito breeding along canal banks, and indirectly by pools and irregular channels", also improper delivery of water into a roadway or roadside ditch or into an uncultivated field was found to form mosquito breeding places, Russell, op. cit., note 64 above, p. 348.

${ }^{66}$ Memorandum regarding malaria control demonstration in Pattukkottai town, by F. W. Knipe, Malaria Officer, Rockefeller Foundation, in TNA GO 2000 (P.H.), 31 May 1938.

${ }^{67}$ The expenditure for the same was met from the provision for epidemic diseases and anti-malarial operations in the Budget for 1938-39. But we have no figure on the expenditures made. Ibid.

${ }^{68}$ C. A. Gill, 'Rice cultivation and Malaria in the Punjab', RMSI 1935, 5: pp. 97-108.

${ }^{69}$ K. R. Rao, op. cit., note 48 above, p. 483.

${ }^{70}$ P. F. Russell, F. W. Knipe and H. R. Rao, 'On agricultural malaria and its control with special reference to South India', IMG 1942, 77: 752. 


\section{Anti-malarial policy in the Madras Presidency}

from growing rice fields also synchronised with the start of vigorous growth of the plants. They disappeared fully when rice had grown taller than one foot. ${ }^{71}$

More wet fallow fields were found each year (usually from mid-June to late August) in the Pattukkottai taluk because it was mainly a single crop area, whereas in the delta rice fields remained wet fallow for shorter periods since it was mainly a two crop area. So the period between the first wetting of the fields and planting was much shorter in the latter than in the former. The consequence was that although $\mathrm{A}$. culicifacies was found in rice fields and channels of the delta, the species never attained a density comparable to that seen in Pattukkottai. The relationship between rice cultivation and malaria depended less on seasonal factors than on the intensity of activity in the field and the stage of growth. Also, farmers in the Pattukkottai taluk used to leave unploughed and fallow fields wet for a period of 2 to 3 weeks during the cultivation process before beginning to work on the seed beds. The effect of this time lag was very significant in terms of the propagation of the malaria vector $A$. culicifacies, because the most dangerous stage of the fallow field was when it was wet and unploughed. ${ }^{72}$

It was, therefore, essentially the "needlessly prolonged" period of wet fallow fields, and the single instead of the double rice crop that seemed to have made the Pattukkottai taluk more malarious. Other factors, such as the presence of waste wet lands, unprotected irrigation wells, and neglected field channels, contributed to the spread of malaria.

The case of the Pattukkottai taluk showed clearly that without an intimate knowledge of the local conditions and their connection with the development of the disease, no effective controls could be designed. While in some areas the extension of rice cultivation could be a preventive measure, in others it would not be so. At times, due to economic and social factors, it was found necessary to resort to other methods of control. For example, in the Pattukkottai taluk, a scheme of intermittent irrigation was tried out, initially on an experimental basis. ${ }^{73}$ It was essentially a method by which water was periodically withheld just enough to allow the surface of fields and channels to become sufficiently dry to kill all the mosquito larvae. Three years of experiments in Pattukkottai showed that this periodic interruption of the water supply to the rice fields "resulted in effective control of anopheles breeding, with no increase in weed growth, and with little or no effect on the yield or quality of grain or the weight of straw."74 During periods of daily rains such as in November, it was not possible to dry the fields sufficiently to control mosquito breeding. But this did not pose a problem, since the density of the vector $A$. culicifacies declined markedly in October and was not found in rice fields when the crop was already more than a foot high, i.e. by November when it was usually about half grown.

Apart from keeping down the larvae by intermittent irrigation, pyrethrum spraying was tried out as another method of control against adult mosquitoes in a few villages

\footnotetext{
${ }^{71}$ P. F. Russell and H. R. Rao, 'The anopheles of rice fields in south-eastern Madras', JMII, 1940, 3: $427-46$.

72 Ibid.

${ }^{73}$ P. F. Russell, F. W. Knipe and H. R. Rao, 'On the intermittent irrigation of rice fields to control malaria in South India', JMII, 1942, 4: 321-40.

${ }^{74}$ Ibid.
} 


\section{R. Muraleedharan and D. Veeraraghavan}

in the Pattukkottai taluk. ${ }^{75}$ In Kesangadu it was found that as a result of spraying the spleen rate fell from 68 per cent in November 1937 to 27 per cent by November 1938 . In the case of villages where pyrethrum spraying was not tried, the spleen rate remained more or less constant. The cost of this method was estimated at 7 annas per capita per annum.

The lessons learned in the Pattukkottai taluk probably represented only a minute part of what remained to be discovered. A comparative survey of the relationship between rice culture and malaria in other regions of the Presidency would perhaps have enabled the government to formulate some broad guidelines and an effective strategy to control malaria. However, despite the lack of such studies, the Pattukkottai case alone showed clearly that preventive measures had to be locationspecific. The experience thus gained brought about a positive change of view on what could be done to check the spread of malaria, as Russell and his co-workers made clear in their suggestions in 1942 to the policy makers in the colonial government: "it is now undoubtedly a fact that for much of rural India malaria control is not only feasible but financially profitable."76

\section{IV}

The case of malaria illustrates the many issues underlying the Government of India's policy on the control of communicable diseases during the early decades of this century. A study of the measures taken against other widely prevalent diseases, such as cholera and smallpox would lead to similar observations. It was a lack not only of finance, but also of a comprehensive knowledge of the relationship between these diseases and local conditions that limited government initiatives against them. The most significant lesson learnt from the limited experiments in Pattukkottai was that expressed by Russell. But it seems to have had a very marginal impact on the anti-malarial policy and programme of the Government of India in the later years. Should this merely be attributed to the outbreak of the Second World War in 1939 and the consequent pushing into the background of all public health measures, especially after the resignation of the Congress ministry in October 1939? Or, should it be seen as the result of wartime economic policies which held welfare activities to be unimportant within the overall structure and policy of the colonial state for whom the interests of the Indian people figured as a poor second to those of the colonial master-Great Britain? Whatever the explanation, the fact remains that interest in developing a national malaria policy was not revived until the early 1950 s.

In post-independence India, a national malaria programme was launched in 1953. It was funded by the central government but was administered by the state governments. The two major strategies of the nation-wide anti-malaria programme were indoor spraying with DDT twice annually in the appropriate seasons combined with fortnightly surveillance, and radical treatment of all detected cases. ${ }^{77}$ This programme had a definite effect but only for the following few years. From 75 million

75 Ibid.

${ }^{76}$ Russell, Knipe, and Rao, op. cit., note 70 above, p. 749.

77 D. Banerji, The making of the health services in India, Part Two, p. 232 (Centre of Social Medicine and Community Health, Jawaharlal Nehru University, New Delhi, 1983). 


\section{Anti-malarial policy in the Madras Presidency}

cases in 1947 , the incidence came down to 49,151 in 1961 and annual mortality was reduced to nil. ${ }^{78}$ A state of near-eradication was reached by the early 1960 s, but thereafter the programme had little effect in controlling the resurgence of malaria.

There are two points to be taken into account here. The Pattukkottai experiment had stressed the need for an understanding of socio-economic factors in the control of malaria, but following the Second World War, DDT and other residual insecticides completely changed the basis on which such planning was done. Consequently, the emphasis was now placed on attacking specific vectors and socio-economic factors were ignored. The result was that, after some initial successes, the strategy failed. There were many reasons for this, but the two most important were the growing resistance of the parasites to the anti-malarial sprays and the fact that the control programme was conceived in isolation to the health services in general. ${ }^{79}$

The need to integrate the malaria control and eradication programme with the rest of the health care system was felt only much later, and, from the mid 1970s, efforts were made to remedy this. However, it took a lot longer for the government to recognize and give greater importance to the role of socio-economic factors in improving the overall level of health among the population.

78 Ibid., p. 238.

${ }^{79}$ N. P. Sinha, 'Malaria eradication: what went wrong?', Economic and Political Weekly (June 26, 1976), pp. 946-7. 